\title{
Clinical Data Suggested Proliferative Enteropathy-Free Horses in Saudi Arabia
}

\author{
Ghanem M Al-Ghamdi \\ Department of Biology College of Science Al-Baha University Al-Baha, Saudi Arabia \\ E. Mail :ghanemalghamdi@gmail.com
}

\begin{abstract}
Proliferative enteropathy (PE) is a recently described disease of horses that is characterized by signs of elevated body temperature, weight loss, diarrhea and death. This disease is caused by Lawsonia intracellularis. The goal of this study was to determine if horses in Eastern Province of Saudi Arabia were clinically affected with L. intracellularis. Total of 246 foals less than two years old were examined. The foals were observed for signs of proliferative enteropathy such as colic, diarrhea, emaciation and edema in the lower parts of the body leading to death. Results recorded 10 foals; with signs of colic ( 2 foals) and emaciation ( 8 foals) however none of the animals was reported to die through one year follow up. Further parasitic testing detected Parascaris equorum, Dictyocaulus arnfieldi and Strongyle infection in these horses. Chemistry profile showed that foals total protein and albumin were within the normal limits. These findings suggest that horses in Saudi Arabia remain proliferative enteropathy free however specific testing including PCR and serology are recommended.
\end{abstract}

Kew words: Horses, proliferative enteropathy, Saudi Arabia.

\section{INTRODUCTION}

The Proliferative Enteropathy (PE) of horses is a newly recognized enteric disease that affects -on most occasions- the weanling animals (Williams et el 1996). Several animal species mainly swine have been reported with PE including horses (Lawson and Gebhart 2000). When PE was described in horses for the first time; Campylobacter spp was thought to be the causative agent (Duhamel and Wheeldon 1982). However when the second equine case was reported, the causative agent, Lawsonia intracellularis, has been well characterized in pigs. Immunohistochemistry using monoclonal antibody to the porcine $L$. intracellularis was used successfully to diagnose Lawsonia antigen (Williams et al.1996). Lawsonia intracellularis is an obligatory intracellular, gram negative, curved organism. The bacterium takes the acid fast (Ziehl Neelsen stains) but does not form spores (McOrist et al. 1995).
Lawsonia intracellularis grows only in a cell culture, intracellularly in enterocytes, and requires a microaerophilic atmosphere (Lawson et al. 1993). PE has been diagnosed in horse cases in North America before the year of 2003. Nevertheless, since then more PE cases are being reported in other parts of the world such as Australia and Europe (McClintock et al. 2004). In pigs, the disease, however, is world-widely distributed (Lawson and Gebhart 2000).

The increase of awareness among veterinarians may explain the increased number of reports of the disease. Whether the diseases has been under diagnosed or misdiagnosed in previous years, the difficulty in the diagnosis of PE might had contributed to the lack of informations in the literature on equine PE. The mode of infection in the horse is not clear. However, the fact that several other species may be affected with PE complicates the epidemiology of the disease. PE-affected foals has been 
reported to shed the organism using fecal polymerase chain reaction (PCR) testing (Lavoie et al 2000). The vast majority of equine PE has been among individual animals, with the exception of outbreaks that affected three breeding farms in Canada (Lavoie et al 2000).

The clinical manifestations of the disease in foals can be tricky. Clinical signs may include depression, anorexia, lethargy and diarrhea (Williams et al. 1996). The diarrhea may range in character from discolored soft feces to watery projectile diarrhea (Duhamel and Wheeldon 1982, Frank et al. 1998, Williams et al 1996). More severe disease characterized by fever and dehydration colic, mainly abdominal pain, which may be seen early in the course of the disease (Schumacher et al 2000). Foals experimentally infected with $L$. intracellularis had decreased appetite, colic, depression, diarrhea and dehydration (Al-Ghamdi et al. 2002). The diarrhea was severe and watery. These signs were clearly observed as early as 14 days after challenge.

Clinical findings of PE in horses are not specific and may resemble other gastrointestinal diseases. Therefore, the clinical diagnosis of PE has been complicated to veterinarians since most diagnosis was based on postmortem examination of suspected cases. Gross and histological findings of lesions in the small intestine area have been key elements in reaching diagnosis (Duhamel and Wheeldon 1982, Frank et al. 1998, Williams et al. 1996). Warthin-Starry silver and Ziehl-Neelsen staining may detect the bacteria in the apical part of the cytoplasm of enterocytes during light microscopy examination. Electron microscopy is also used to visualize straight or curved bacilli within the cytosol of enterocytes. Immunohistochmesitry (IHC) utilizing monoclonal antibodies prepared against porcine $L$. intracellularis are used against intestinal tissue samples (McOrist et al 1987). Redbrownish IHC staining in the apical cytoplasm indicates affected intestinal cells.

The aim of this study is to examine horses in Saudi Arabia for the presence of proliferative enteropathy using clinical evaluation. Horse farming in Saudi Arabia is not linked to swine and therefore the epidemiology of the disease will be of great interest.

\section{MATERIALS AND METHODS}

Twenty six horse farms located in the Eastern Province of Saudi Arabia were visited. During the visit, 246 animals less than two years were observed for clinical signs suggestive of PE including colic, diarrhea, emaciation and edema in the lower parts of the body leading to death. Fecal samples were collected to determine the existence of other diseases including Salmonellosis and parasitic infection. Salmonella culture was performed on ten animals that showed clinical disease. In the meantime fecal examination for parasitic infection was performed using direct smear, flotation and sedimentation. Total protein and albumin were determined in suspected animals (Smith 2002).

\section{RESULTS}

The results were summarized in Table 1. Clinical evaluation of 246 foals residing 26 farms that were younger than two years of age for signs suggestive of proliferative enteropathy (PE) including colic (2), diarrhea (10) and emaciation (8) with a total of 10 affected animals. However during a one-year follow none of these animals were reported to die despite no administration of $L$ intracellulrais specific treatment. 
Table 1: Data Summery

\begin{tabular}{|c|c|c|c|c|c|c|}
\hline 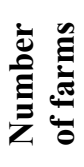 & 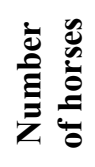 & 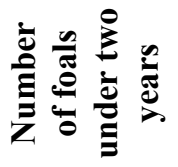 & 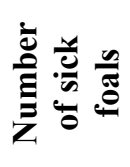 & 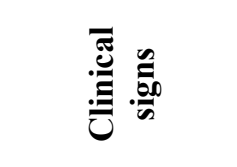 & 焉 & 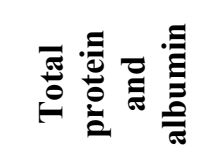 \\
\hline 26 & 302 & 246 & 10 & $\begin{array}{c}\text { Colic, diarrhea, } \\
\text { emaciation }\end{array}$ & 0 & $\begin{array}{l}\text { Within normal } \\
\text { limits }\end{array}$ \\
\hline
\end{tabular}

In addition signs of severe edema in the lower parts of the body were not detected. In the meantime, no animals tested positive for Salmonella in a single culture testing. Finally, the total protein and albumin profiles were within the normal limits in the ten clinically ill foals.

\section{DISCUSSION}

The clinical signs of PE are not specific and may mimic other enteric diseases. However, the presence of colic, diarrhea and emaciation as well as edema in the lower parts of the body in foals less than two years of age are very suggestive of PE. Further clinical chemistry analysis mainly total protein and albumin help to differentiate the disease. Finally, unless specific antibiotic therapy was initiated, death is usually the ultimate ending of the disease (Schumacher, et al. 2000, Williams et al, 1996). During this study, few horses had signs suggestive of PE, however chemistry profile did not support these finding. In a previous work, colic was most common health challenge to horse owners however those cases were mostly adults and surgical problem (Al-Ghamdi 2008). In the meantime, testing to rule out other enteric diseases including parasitic screening detected parasitic infection mainly Parascaris equorum, Dictyocaulus arnfieldi and Strongyle (Data not shown). Previous study that looked at the incidence of the disease over a period of almost ten years showed that PE was the second most commonly diagnosed enteric pathogens after Salmonella in foals less than 12 months (Al-Ghamdi et al. 2007). The study also was based on direct testing and indicated that the disease was only detected in foals with enteric disorders. In this study, PE may not be completely ruled out, since serology and fecal PCR are applied. However, the later tests require the use of L. intracellularis Ag which may not be justified at the moment. In the meantime, L. intracellualris is likely to be a terminating disease if the appropriate treatment were not initiated. Finally, the negative results of Salmonella indicates the need for serial culture to rule it out.

The epidemiology of $L$. intracellularis is complicated and involves many animal species including swine, in which a great deal of health impact and economic loss were described. Examination of wild rats on pigs farms detected over $70 \%$ prevalence of $L$. intracellularis with large number of organisms being shed implicating the importance of rodents reservoir in the epidemiology of PE (Collins et al. 2011). However the importance of rats as a risk factor in disease maintenance and transmission is dependent on the shedding of the organism by the original host. Swine are not raised in Saudi Arabia. In addition, the species -specific susceptibility suggests that the disease is more severe when the agent originated from the same host. (Vannucci et al. 2012) Finally, the presence of other wild hosts that may come in contact with 
horses is very limited. Therefore, the risk of having PE among equine population remains low.

In human, inflammatory bowel disease (IBD) including Crohn's disease (CD) and ulcerative colitis (UC) are known to be induced by multifactorial agent including infectious and genetic elements (Bouma G and Strober W 2003, Greenstein R J 2003.

Ohkusa $\mathrm{T}$ et al. 2004). The use of PCR utilizing $L$ intracellularis -specific 16SII primers indicated that there is no association between IBD and $L$ intracellularis (Michalski et al. 2006). Since this organism is known to cause the disease in young animals, therefore it is unclear whether the age factor was responsible for the failure of detecting positive cases. Another organism that was thought to play a role in Crohn's disease (CD) is Mycobacterium avium subspecies paratuberculosis (Abubakar et al. 2008). This organism has been reported in several animal species in Saudi Arabia mainly Camels (AlHajri et al. 2007, Alharbi et al. 2012). Limited data is available on the disease in human in Saudi Arabia, however chances for camel role in disease transmission is high since it is not unusual for people to drink fresh unpasteurized camel milk. Therefore it will be great to examine the role of these intracellular organism in IBD in human.

Further work is required to determine the existence of $L$ intracelluaris in horses and possibly other animal species. In addition, risk factors of Crohn's disease (CD) in Saudi Arabia need to be determined.

\section{REFERENCES}

Abubakar I, Myhill D, Aliyu SH, Hunter PR. (2008). Detection of Mycobacterium avium subspecies paratuberculosis from patients with Crohn's disease using nucleic acid-based techniques: a systematic review and metaanalysis. Inflammatory Bowel Diseases , 14(3): 401-410.
Al-Ghamdi G.M., Gebhart C.J., Hayden D.W. and Ames T.R. (2006). Documentation of Proliferative Enteropathy in Foals, Scientific Journal of King Faisal University., 7;2:147-154.

Al-Ghamdi G.( 2008). Most common diseases impacting horse health in the major regions of Saudi Arabia. J Vet. Animal. Adv. 7:5:581-583.

Al-Ghamdi G.M., Guedes R, Ames T, Sage A.M, Hayden D. W, Neubauer A. and Gebhart C. J. (2012). Reproduction of proliferative enteropathy in foals after challenge with Lawsonia intracellularis infected porcine intestinal mucosae homogenate. B. Vet Med J. In Press.

AlHajri, S. M, Alluwaimi, A. M, (2007). ELISA and PCR for evaluation of subclinical paratuberculosis in the Saudi dairy herds. Vet Microbiol. 121: 384385.

Alharbi, K. B, Al-Swailem, A, Al-Dubaib, M. A, Al-Yamani, E, Al-Naeem, A, Shehata M, Hashad, M. E, Albusadah, K. A, Mahmoud, O. M ( 2012). Pathology and molecular diagnosis of paratuberculosis of camels. Trop Anim Health Prod. 44:173-7.

Bouma G, Strober W.(2003). The immunological and genetic basis of inflammatory bowel disease. Nat Rev Immunol., 3(7):521-533.

Collins AM, Fell S, Pearson H, Toribio JA. (2011).Colonisation and shedding of Lawsonia intracellularis in experimentally inoculated rodents and in wild rodents on pig farms. Vet Microbiol.,150 (3-4):384-8.

Duhamel, G.E., Wheeldon, E.B. (1982). Intestinal adenomatosis in a foal. Vet Pathol. 19:447-450.

Frank, N., Fishman, C.E., Gebhart, C.J., Levy, M. (1998). Lawsonia intracellularis proliferative enteropathy in a weanling foal. Equine Vet. $J$. 30:549-552.

Greenstein RJ.(2003). Is Crohn's disease caused by a mycobacterium? Comparisons with leprosy, tuberculosis, and Johne's disease. Lancet Infect Dis, 3(8):507-514.

Lavoie, J.P., Drolet, R., Parson, D. Leguillette, R., Sauvageau, R. Shapiro, J., Houle, L., Halle, G. and Gebhart, C.J. (2000) Equine proliferative enteropathy: 
A cause of weight loss, colic, diarrhea and hypoproteinaemia in foals on three breeding farms. Equine Vet J. 32: 418425.

Lawson, G.H.K. and Gebhart, C.J. (2000). Proliferative enteropathy. J Comp Path. 122: 77-100.

Lawson, G.H.K., McOrist, S., Jasni, S. and Mackie, R.A. (1993). Intracellular bacteria of porcine proliferative enteropathy: cultivation and maintenance in vitro. J. Clin. Microbiol. 31: 1136-1142.

McClintock S.A. and Collins AM. (2004). Lawsonia intracellularis proliferative enteropathy in a weanling foal in Australia. Aust Vet J:82;12:750-2

McOrist, S., Boid, R. and Lawson, G.H.K. (1987). Monoclonal antibodies to intracellular Campylobacter-like organisms of the porcine proliferative enteropathies. Vet Rec. 121:421-422.

McOrist, S., Gebhart, C.J., Boid, R. and Barns, S.M. (1995). Characterization of Lawsonia intracellularis gen. nov., sp. nov., the obligately intracellular bacterium of porcine proliferative enteropathy. Int J Syst Bacteriol. 45:820-
Michalski CW, Di Mola FF, Kümmel K, Wendt M, Köninger JS, Giese T, Giese NA and Friess H. (2006). Lawsonia intracellularis infection. BMC Microbiology, 6:81

Ohkusa T, Nomura T, Sato N. (2004). The role of bacterial infection in the pathogenesis of inflammatory bowel disease. Intern Med, 43 (7): 534-539.

Schumacher, J., Shumacher, J., Rolsma, M., Brock, K.V. and Gebhart, C.J. (2000). Surgical and medical treatment of an Arabian filly with proliferative enteropathy caused by Lawsonia intracellularis. J. Vet Intern. Med. 14: 630-632.

Smith, B.P. (2002). Large Animal internal medicine; 3rd Edition; a Harcourt health sciences company Ltd; USA.

Vannucci F., Pusterla N, Mapes S, Gebhart C. (2012). Evidence of host adaptation in Lawsonia intracellularis infections. Veterinary Research, 43:53.

Williams, N.M., Harrison, L. and Gebhart, C.J. (1996). Proliferative enteritis in a foal caused by Lawsonia interacellularis like bacteria. J Vet Diagn Invest, 8: 254-256.

\section{ARABIC SUMMARY}

الاراسات الاكلينيكية تقترح خلو الخيول في اللملكة العربية السعودية من مرض الاعتلال المعوي

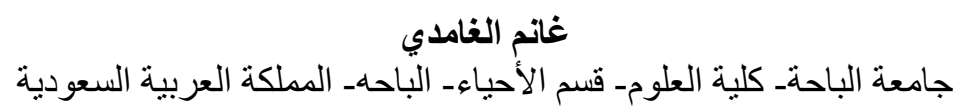

مرض الاعتلال المعوي من الأمر اض التي تم وصفها موخرا في الخيول والتي تتميز بأعراض منها

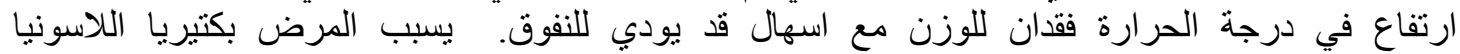

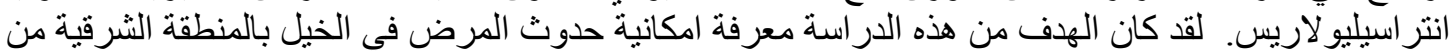

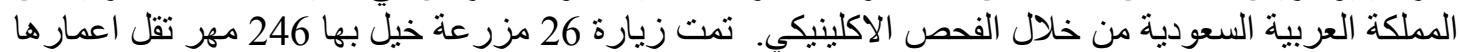

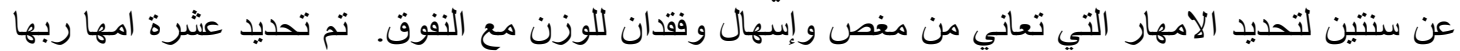

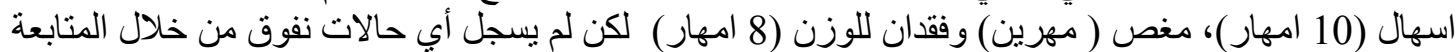

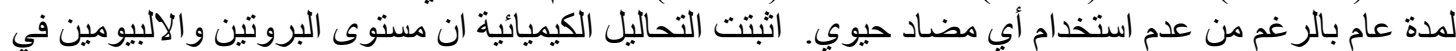

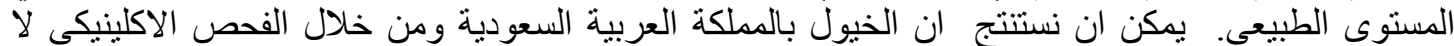

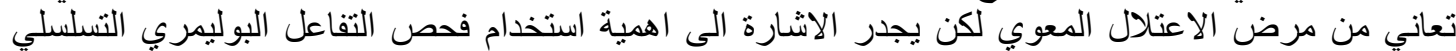

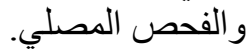

